\title{
Evaluation of the Acid Baking Technique to Decrease the Phosphorus Content of the Iron Ore
}

\author{
Leonardo Martins da Silva ${ }^{*}{ }^{\circ}$, Marisa Nascimento ${ }^{b}$, Elizabeth Mendes de Oliveira ${ }^{c}$, Anderson \\ Vergilio de Queiroz ${ }^{a}$, Márcio Teodoro Fernandes ${ }^{a}$, Jose Adilson de Castro ${ }^{a}$ (D)
}

\author{
${ }^{a}$ Universidade Federal Fluminense, Av. dos Trabalhadores 420, Vila Sta. Cecília, CEP 27255-125, Volta \\ Redonda, RJ, Brasil \\ ${ }^{b}$ Centro de Tecnologia Mineral, Avenida Pedro Calmon, 900, Cidade Universitária, CEP 21941-908, \\ Rio de Janeiro, RJ, Brasil \\ ${ }^{c}$ Centro Federal de Tecnologia, Rua do Areal, 522, Pq Mambucaba, CEP 23953-030, Angra dos Reis, RJ, Brasil
}

Received: March 17, 2019; Revised: June 26, 2019; Accepted: July 02, 2019

Unlike the available mineral resources, the steelmaking processes have demanded raw material with lower phosphorus content to decrease the costs, energy use, and the residue generated within the steel plant. One alternative is to develop pretreatment of the iron ore concentrates producing raw materials with lower phosphorus. Depending on the mineral structure, a heat treatment combined with leaching could be an efficient way to achieve concentrates with low phosphorus (less than $0.01 \%$ ), suitable for steelmaking processes. A fast and efficient way of applying energy to iron ore particles is the use of microwave to heat the particles. Thus, we propose a treatment using microwave heating while mixing with a dilute aqueous solution of sulfuric acid, followed by quenching during leaching with water, as a feasible route for the phosphorus removal from iron ore particles. We performed a design of experiment (DOE) to investigate the optimal conditions of heating and leaching, which maximize the rate of phosphorus removal. The structure of the iron ore particles after their treatment with microwave energy was observed by scanning electron microscopy (SEM). Thus, we analyze the optimal conditions for heating and leaching, the structure of the iron ore particles and which mechanism and rate equations are controlling the phosphorus removal. The results indicated that the average heating time is $10 \mathrm{~min}$, the size of the crack of the order of $20 \mu \mathrm{m}$ and a leaching time of 8 min are adequate to achieve less than $0.01 \%$ of phosphorus. We demonstrated that under the most favorable combination of conditions for heating followed by leaching proposed in this study, the removal of the phosphorus content in the iron ore samples could reach $100 \%$.

Keywords: Microwave, leaching, phosphorus, iron ore, kinetic model, DOE.

\section{Introduction}

Iron ore is the most widely mined mineral resource of the Earth's crust, being the main raw material used in the steel industry. However, the amounts of the phosphorus and alumina combined with the iron molecules in the mineral complexes have continuously increased. The mineralogy and variety of the complex phosphorous structure are the major challenges to remove them using the traditional mineral processing technologies. In the metallurgical processes of iron production, the formation of complex compounds with phosphorus leads to significant impacts on the costs of the steel production. ${ }^{1}$ Therefore, the search for alternative routes for the removal of phosphorus from iron ores has driven the research of new techniques, which combine the optimization of the mining with lower tailing and the residues generation during the beneficiation processes. It is generally accepted that phosphorous in iron ore is mostly complexed with goethite molecules, $\mathrm{FeO}(\mathrm{OH})$, as a solid solution $^{1}$ or adsorbed on the surface of the particles ${ }^{2,3,4}$.
The common molecular structure observed for the complex is schematized in Figure 1.

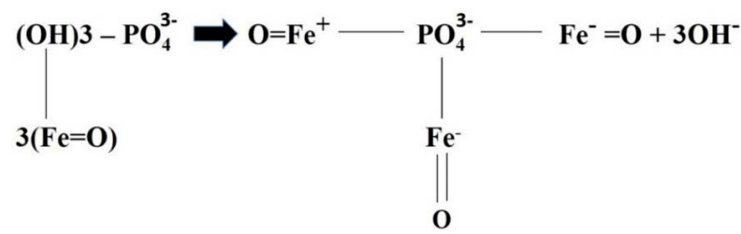

Figure 1. Molecular structure of the phosphorus occurrence in goethite.

It is recognized that the structural arrangement of the phosphorous complex within the iron ore plays a crucial role in the possible mechanisms able to remove them from the mineral phases. The ternary adsorption and surface precipitation processes involve the dissolution of the goethite crystal and the subsequent adsorption of iron on the phosphate bonding surface. The precipitation surface of the anions involved in the model comprises the dissolution of the goethite crystal, which shows the iron ions in the crystalline structure. 
The steps involved are listed as Step 1 - The arrival of the phosphate forms a mono-toothed or bi-toothed complex with the hydroxyls on the goethite surface. Step 2 - The adsorbed phosphate acts as a sorption site for dissolved iron, forming a ternary complex and reducing the concentration of iron in solution. Step 3 - The goethite is dissolved to then supply the iron ion in solution, which can thus adsorb phosphate on its surface. It is known that adsorbed anions can form ternary complexes with metals in solution. Step 4 - The adsorbed iron acts as an adsorption site for the phosphate. The distribution of phosphorus along the goethite crystals impairs the efficient use of physical separation techniques, thus requiring the use of chemical separation techniques 5 . However, the authors report that the process of chemical leaching using alkaline solutions was not effective for dephosphorization ${ }^{6}$. This fact occurs due to the reprecipitation of phosphorous with other metallic ions released during the leaching process. Alternatively, depending on the mineralogy, the temperature during the leaching process can play an important role, as shown in Figure 2. The presence of an M3P species indicates the goethite-phosphorus complex.

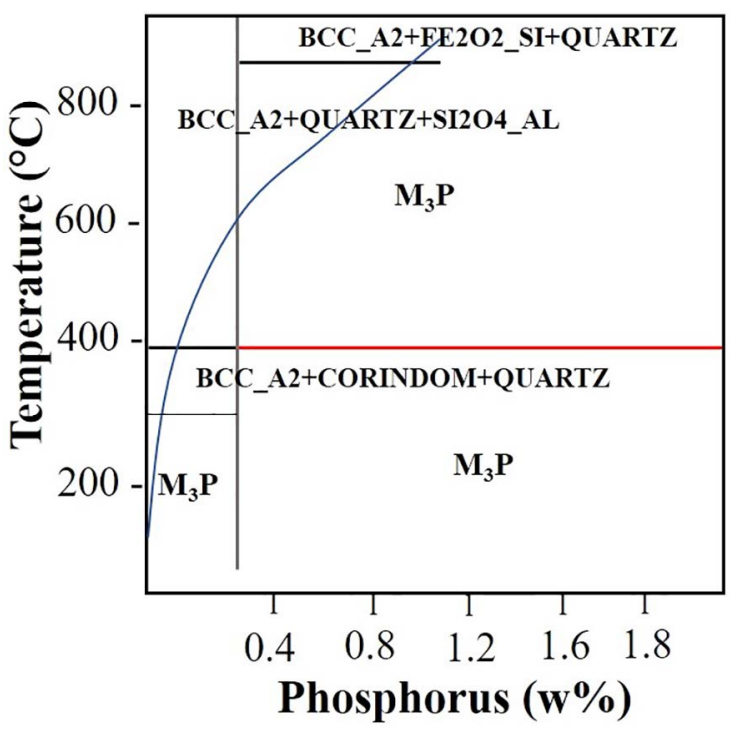

Figure 2. Phase diagram details in the range of phosphorous concentration occurrence for an iron ore with the composition: $\mathrm{Fe}(60 \%), \mathrm{O}(20 \%), \mathrm{Si}(10 \%)$ and $\mathrm{Al}(10 \%)$, calculated using Thermocalc $\AA$ software.

Figure 2 shows the phase diagram of iron with fixed $\mathrm{Fe}, \mathrm{O}$, $\mathrm{Si}$ and $\mathrm{Al}$, and variable $\mathrm{P}$ contents, where the M3P complex is stable at temperatures between 0 and $300^{\circ} \mathrm{C}$, which agrees with the complex molecule structure, shown in Figure 1.

When phosphorus is found in solid solution in the goethite phase, the heat treatment process of the iron ore particles can be an efficient technique to its removal ${ }^{7}$. Such treatment enables the structural rearrangement of goethite, which is converted into hematite and facilitates the release of the phosphorus to the acid leaching process.
However, the heating method should be defined. The pretreatment using microwave energy during the mining and metallurgy process of various ores is considered a new method developed in the last decades ${ }^{8}$. Their results are exciting and demonstrate that microwave energy has good potential for mineral treatment and metallurgical processes. Pretreatments using microwave energy of iron ore are based on the concept of the difference in the absorption potential of the microwave energy observed in the various minerals in the ore minerals would have chemical reactions, phase transitions or specific microstructural changes under microwave radiation. The physical process of microwave heating is described by the complex dielectric constant and (permittivity) ${ }^{9}$. Due to the application of microwave irradiation to mineral particles, differential thermal stresses around the grain boundaries are intensified and thus considered as the main driving force for the particle cracking ${ }^{10}$. Analyses indicated that for particles where strong absorptive minerals are found in a non-absorbent matrix, the minerals of the ore particles heat extraordinarily fast compared to the gangue ${ }^{11,12}$. According to these studies, thermal expansion due to microwave absorption dilates the matrix and creates tensile stress around the grain boundaries. Thermal stress and fractures were observed in iron ore samples submitted to different heating rates by the emission of microwave energy ${ }^{13}$.

Similar approaches have been reported ${ }^{14-17}$. Processes of acid baking at different temperatures were developed ${ }^{14}$. Initially, acid baking was used at a low temperature, which resulted in the solubilization of rare earth and impurities during leaching ${ }^{15}$. In the 1980 s, this was replaced by heating at 500 $900{ }^{\circ} \mathrm{C}$, termed bake at high temperature, which increased the extraction of thorium and phosphorus, leading to the benefits of a simplified process purification ${ }^{16,17}$. In this study, we combine the technique of acid baking with microwave heating and rapid cooling in water. Although the microwave acid baking process exhibits the same properties of the conventional process, it has the advantage of rapid heating in the order of minutes, while in conventional acid baking the treatment is developed during hours. The fundamental feature of this route is the integration of a process with the rapid heating of the iron ore particles mixed with the mass of a dilute aqueous solution with sulfuric acid.

Therefore, in this work, we propose a route for the removal of the phosphorus content, through the hydrogen sulfide with controlled leaching technique. Thus, we proposed an integrated route of beneficiation process with the heating of the iron ore particles to around $1000^{\circ} \mathrm{C}$, where the release of phosphorus is possible. Then, the iron ore is water-cooled to room temperature suffering a rapid temperature drop. The experiments were carried out following a design of experiment methodology (DOE) using factorial planning with central and axial points. Numerical data regressions were carried out to draw general conclusions on the results. Kinetic leaching models were used to discuss the controlling mechanism along the reaction time. 


\section{Materials and Methods}

\subsection{Characterization of iron ore}

X-ray diffraction (XRD) and scanning electron microscopy (SEM) were performed for the characterization of the sample treated and not treated with microwave energy to evaluate structural changes during reactions.

The sample of iron ore originated in the Quadrilátero Ferrifero Mining, a region of Minas Gerais, Brazil. All sample ( $>100 \mathrm{~mm}$ ) were crushed, obtaining particles smaller than $5 \mathrm{~mm}$ and comminuted in a bar mill at the facilities of the Center for Mineral Technology - CETEM, generating particle size fractions smaller and bigger than $0.234 \mathrm{~mm}$. The powders were analyzed using x-ray diffraction and the Rietveld method of quantification.

Figure 3 shows the X-ray diffraction spectrum of the iron ore used in this investigation, and Table 1 shows the mineralogical composition of the iron ore sample.

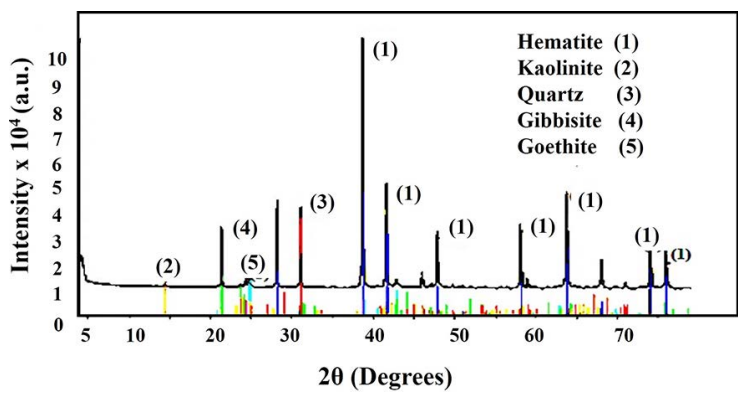

Figure 3. Representative $\mathrm{x}$-ray diffraction spectrum of the iron ore sample.

Table 1. Mineralogical composition of the iron ore used in this study

\begin{tabular}{ccc}
\hline Mineral phase & Chemical Formulae & Mass (w\%) \\
\hline Hematite & $\mathrm{Fe}_{2} \mathrm{O}_{3}$ & 72.89 \\
Kaolinite & $\mathrm{Al}_{2} \mathrm{Si}_{2} \mathrm{O}_{5}(\mathrm{OH})_{4}$ & 4.64 \\
Quartz & $\mathrm{SiO}_{2}$ & 12.05 \\
Gibbsite & $\mathrm{Al}(\mathrm{OH})_{3}$ & 3.18 \\
Goethite & $\mathrm{FeO}(\mathrm{OH})$ & 7.25 \\
\hline
\end{tabular}

Hematite, quartz, and goethite were the main phases identified by the X-ray diffraction method, where the absence of apatite and aluminosilicate compounds was observed. The chemical analysis was carried out by inductively coupled plasma optical emission spectrometry (ICP-OES) method performed at CETEM. The phosphorus content in the ore sample was $346 \mathrm{mg} . \mathrm{kg}^{-1}$, corresponding to $0.0346 \%$. The iron ore with this amount of phosphorus would be treated as residue in the mining site. The scanning electron microscopy (SEM) analyses were carried out at Universidade Federal Fluminense - UFF. The SEM analysis were used to verify the formation of the crack during the microwave heating and quenching in the leaching acid dilute solution.

\subsection{Effects of the acid baking process on iron ore using microwave energy}

A conventional microwave reactor (Model: PMS-24) with $1200 \mathrm{~W}$ of power and emitting microwave radiation with a frequency of $2450 \mathrm{MHz}$ was used to treat the ore fines. In the conventional microwave reactor, the microwaves are generated by a magnetron, located in the top right of the reactor. Thus, the iron ore sample was placed in the lower left are of the equipment, where greatest microwave radiation intensity observed. The inside of the reactor had dimensions of $260 \mathrm{~mm}$ (height), $460 \mathrm{~mm}$ (width), and $320.3 \mathrm{~mm}$ (length). The samples were treated varying time and the output power of the microwave oven under air atmosphere for all samples. When the reaction time was completed in the reactor, the sample was discharged into a reactor containing $500 \mathrm{~mL}$ of water at room temperature. The formation of fractures in the iron ore particles can be observed comparing figures $4 \mathrm{~A}$ and $\mathrm{B}$.

The untreated ore fines structure is dense and without any type of fracture or inclusions. An after treatment under microwave power of $1200 \mathrm{~W}$ some fractures can be observed (Figure 4B). Microwaves radiations thus induce the rapid heating, that generates cracks in the ore, resulting in a possible weakening of the particles and enhancing the contact of the leaching solution. The analysis indicated that the interaction of the magnetic field with some materials contributes greatly to the heating rate when compared to materials exposed to the electric field ${ }^{18}$.
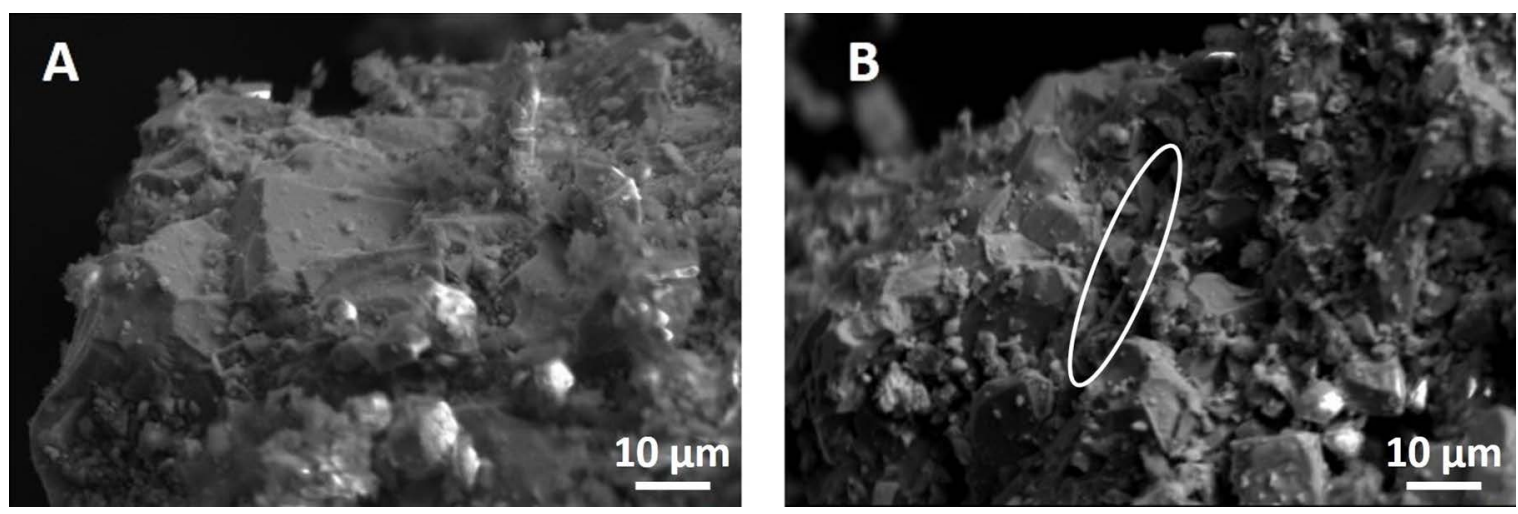

Figure 4. SEM images of the iron ore fines before (A) and after (B) microwave energy treatment. 
The maximum temperature occurs due to the increase of the magnetic saturation and the remaining magnetization of the iron ore samples ${ }^{13}$. When the $2450 \mathrm{MHz}$ frequency is used, the alignment of the molecules and their relaxation to the state of disorder occurs $4.9 \times 10^{9}$ times per second, which results in rapid and efficient heating. However, the heating in this process depends on the relaxation time of the sample, which is defined as the time required to sort and clutter $63 \%$ of the sample completely ${ }^{18}$. The microwave energy provides a possible mechanism to induce rupture between the ore and the gangue minerals or the host rock ${ }^{13}$. This can be explained by the differential absorption of the microwave energy and the thermal differences given by the coefficients of expansion between the various mineral phases in the iron ore particles. It has been suggested that the microwave heating process can accumulate internal energy in the materials and was concluded the samples accumulated enough energy to promote cracking during quenching, and also that increasing the sample mass allowed to decrease the required heating time ${ }^{13}$. The rapid heating of the ore occurs due to the high energy of the microwaves, which can be absorbed in minerals that contain high iron content $^{19}$. On the other hand, the matrix with a greater amount of gangue of difficult absorption of microwave energy can generate large thermal gradients that allow tension to occur in the particle. This thermal stress causes microfractures along the borders of the mineral grains, and as a result, the sample of iron ore becomes more favorable for grinding, with the fractures produced being a function of the electric field strength ${ }^{20}$. Numerical simulations of the heating of pyrite-containing samples showed that the rapid heating occurs with microwave contact in a transparent matrix and that the sample was fractured due to temperature gradients across the grain boundaries ${ }^{20}$. The proposed route of unit operations for reducing the phosphorus content using microwave energy and acid baking followed by leaching is shown in Figure 5.

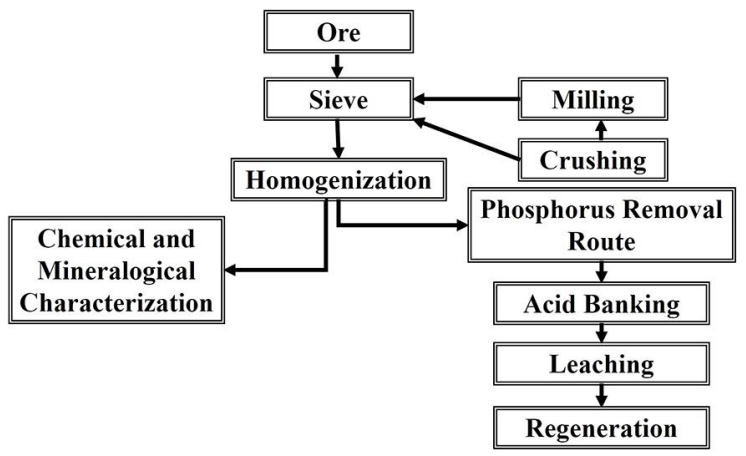

Figure 5. Methodological flowchart of the experimental runs using microwave energy for acid baking followed by water leaching.

For the evaluation of the acid baking process using microwave energy, the central composite rotational DOE technique (CCRD) was used to evaluate the influence of the independent variables time and power of the microwave oven during the interaction of the $50 \mathrm{~g}$ iron ore sample with an average particle size of $0.234 \mathrm{~mm}$ percolated by $25 \mathrm{~g}$ of concentrated sulfuric acid. Using experimental planning based on statistical principles, useful information can be extracted from the system under study by performing a minimum number of experiments.

Table 2 presents the values used in the factorial planning within each experimental coefficient range and within the levels $(-1,1)$, and outside these levels.

The values presented in Table 2 were stipulated, considering the mean between the upper and lower axial values. Table 3 presents the results of interactions between the independent variables followed by the surface response values.

Table 2. Levels used in factorial planning for controllable variables

\begin{tabular}{cccccc}
\hline Variables & $\mathbf{- 1 . 4 1}$ & $\mathbf{- 1}$ & $\mathbf{0}$ & $\mathbf{1}$ & $\mathbf{+ 1 . 4 1}$ \\
\hline Time (min) & 2 & 4 & 6 & 8 & 10 \\
Furnace power $(\%)$ & 1 & 25 & 50 & 75 & 100 \\
\hline
\end{tabular}

Table 3. The planning parameters used in the DOE and the Results obtained for the response variables.

\begin{tabular}{cccccc}
\hline Test & Time $(\mathbf{m i n})$ & Power $(\%)$ & P-removal (w\%) & Fe-removal (w\%) & Ratio-P/Fe (kg.kg-1) \\
\hline TEST 1 & 4 & 25 & 1.95 & 0.65 & 2.99 \\
TEST 2 & 8 & 25 & 90.10 & 0.09 & 1015.98 \\
TEST 3 & 4 & 75 & 44.86 & 0.43 & 105.44 \\
TEST 4 & 8 & 75 & 46.15 & 0.86 & 53.60 \\
TEST 5 & 2 & 50 & 52.18 & 0.16 & 322.31 \\
TEST 6 & 10 & 50 & 4.13 & 0.09 & 47.96 \\
TEST 7 & 6 & 1 & 2.56 & 0.09 & 27.79 \\
TEST 8 & 6 & 100 & 4.43 & 0.09 & 46.98 \\
TEST 9 & 6 & 50 & 100.00 & 0.10 & 281.90 \\
TEST 10 & 6 & 50 & 62.26 & 0.09 & 669.19
\end{tabular}




\subsection{Kinetic analysis of the leaching process}

The kinetics of the leaching technique in a tank with controlled agitation was evaluated using a volume of 300 $\mathrm{mL}$ of water, used as the leaching agent, added to a $500 \mathrm{~mL}$ beaker, which worked as the reactor. Samples of different masses of iron ore were reacted according to a design of experiment, including axial levels of -1.41 to +1.41 (being defined by the equation $2^{\mathrm{k}}$ where $\mathrm{k}=$ number of levels). The residence time variable of the sample in the microwave oven and the variation of the microwave oven power were monitored. For the particles leaching process, the reaction mixture was stirred with the aid of a IKA model RW20 mechanical stirrer. After completion of the reaction time, the mixture was filtered under vacuum on a Büchner funnel and brought to the oven for drying at $40^{\circ} \mathrm{C}$ for 1 hour. All samples were then sent for quantitative analysis of the phosphorus content, using ICP-OES technique at CETEM. The analysis of the effect of the interaction between the different variables was carried out using the software Statistica 8.0 (StatSoft), in order to obtain the combination of values and the parameters correlations.

The calculation of the percentage of removal is as follows:

$$
(w \%) \frac{C_{f}-C_{0}}{C_{0}} \times 100
$$

Where $c_{o}$ and $c_{f}$ are the phosphorous weight percentages of the iron ore samples, before and after leaching process, according to Graham $1973^{21}$, the calcination of iron ore causes the dehydration of goethite to hematite, releasing phosphorus in solution as an acid-soluble compound. Then, the dephosphorization reaction will occur using the sulfuric acid from the particles as a leaching medium, as shown in equation 2.

$$
C a_{10}\left(P O_{4}\right) 6 X_{(s)}+20 H^{+} \rightarrow 6 H_{3} P O_{4}+10 C a^{2+}+H_{2} X
$$

According to equation 2, the interaction of $20 \mathrm{H}^{+}$ions is required for the dephosphorization reaction of the iron ore to occur. The sulfuric acid dissociation in aqueous solution is calculated using the HSC Chemistry software, as shown in Figure 6. It is known that the acidity of the first dissociation of the molecule $\mathrm{H}_{2} \mathrm{SO}_{4}$ only involves the formation of the $\mathrm{H}_{3} \mathrm{O}^{+}$and $\mathrm{HOSO}_{3}$ species, with the second dissociation being necessary to release the $\mathrm{H}^{+}$ions in the $\mathrm{HOSO}_{3}^{-}$anion. The hydration of the dimer $\left(\mathrm{H}_{2} \mathrm{SO}_{4}\right)_{2}$ always conducts ionic forms, but the dissociation becomes easier for larger systems where there is an increase in the number of water molecules or the number of sulfuric acid molecules. The equilibrium composition of sulfuric acid as a function of temperature using the HSC Chemistry TM 7.1 equilibrium modulus can be seen in Figure 6, showings that the sulfuric acid solution is fully decomposed at temperatures above $200^{\circ} \mathrm{C}$.

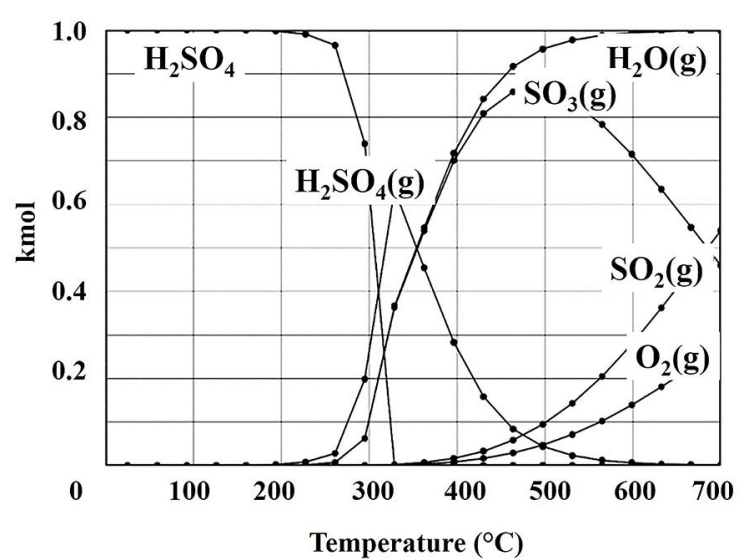

Figure 6. Composition of sulfuric acid at the equilibrium as a function of temperature using the HSC Chemistry ${ }^{\circledR} 7.1$ equilibrium modulus (sulfuric acid at $1 \mathrm{kmol}$, total pressure: $1 \mathrm{bar}$ ).

As can be seen in Figure 6, the decomposition of sulfuric acid is negligible at temperatures below $250^{\circ} \mathrm{C}$. In the tests with the application of microwaves, all mass of acid was evaporated with a maximum contact time of 10 minutes, mainly due to the conversion of $\mathrm{H}_{2} \mathrm{SO}_{4(\mathrm{l})}$ to $\mathrm{H}_{2} \mathrm{SO}_{4(\mathrm{~g})}$. Like this between $\mathrm{HCl}, \mathrm{HNO}_{3}$, and $\mathrm{H}_{2} \mathrm{SO}_{4}$, sulfuric acid is the most effective acid for the dephosphorization of the iron ore ${ }^{22}$.

\subsection{Calculations of the speed controlling phase of phosphorus removal.}

The leaching of iron ore in sulfuric acid solutions includes a heterogeneous reaction and, assuming that the iron ore particles have a spherical geometry and the chemical reaction is the speed controlling step, the expression of the unreacted core model can be used to describe the dissolution kinetics process:

$$
1-(1-\propto)^{\frac{1}{3}}=k_{r} . t
$$

In which:

$\alpha=$ reduced fraction of the phosphorus element in the iron ore sample $\left(\mathrm{kg} \cdot \mathrm{kg}^{-1}\right)$;

$k_{r}=$ kinetic constant of the chemical control mechanism $\left(\mathrm{s}^{-1}\right)$;

$t=$ leaching process time (s).

In the same way, if the diffusion of the reagent occurs through the ore layer, it becomes the step of the control values.

The following expression represents the diffusional control model through the ash layer of the iron ore particles:

$$
\left[1-3(1-\propto)^{\frac{2}{3}}+2(1-\propto)\right]=k_{d} . t
$$

In which:

$\alpha=$ reduced fraction of the phosphorus element in the iron ore sample $\left(\mathrm{kg}^{\mathrm{kg}} \mathrm{kg}^{-1}\right)$;

$k_{\mathrm{d}}=$ kinetic constant of the diffusional control mechanism $\left(\mathrm{s}^{-1}\right)$;

$t=$ leaching process time (s). 
According to equations (3) and (4), when the chemical reaction is the controlling step, the plot of $\left[1-(1-\alpha)^{1 / 3}\right]$ versus time will result in a straight line with the $k_{r}$ slope. Conversely, when the process is controlled by the diffusion through the solid product layer, a plot of $\left[1-3(1-\alpha)^{2 / 3}+2(1-\alpha)\right]$ versus time, a straight line is obtained with a slope $k_{d}^{23}$.

\section{Results and Discussion}

\subsection{Effects of the time and microwave oven power variables as a function of the percentage of phosphorus and iron removal}

The interaction between the different independent variables as a function of the phosphorus content reduction was presented in Table 3 . In the process, $50 \mathrm{~g}$ of percolated sample were used in $25 \mathrm{~g}$ of concentrated sulfuric acid inside the microwave oven. The sample was then leached in water with stirring at $620 \mathrm{rpm}$. The removal values of $100 \%$ of $\mathrm{P}$ and $0.1 \%$ of Fe were observed in test 9 , which was considered as the optimum conditions for reducing the content of phosphorus in the iron ore combining with the minimum iron loss.

Figures 7 and 8 show the $3 \mathrm{~d}$ and $2 \mathrm{~d}$ profiles of the phosphorus and iron content reduction as a function of the contact time of the sample with the microwave energy and the power applied by the furnace in the percolated iron ore sample.

Figure 8 shows the contours plots of the percentage of iso-values of the phosphorus and iron content removal as a function of the contact time of the sample with the microwave energy and the power applied by the furnace to the percolated iron ore samples.

In Figure 8 shows that the best ratio of phosphorus and iron content to reduction rates in iron ore particles with lower iron loss occurred with the microwave oven power applied in values close to $30 \%$, with a residence time of the percolated sample in the oven over 9 minutes.

(A)

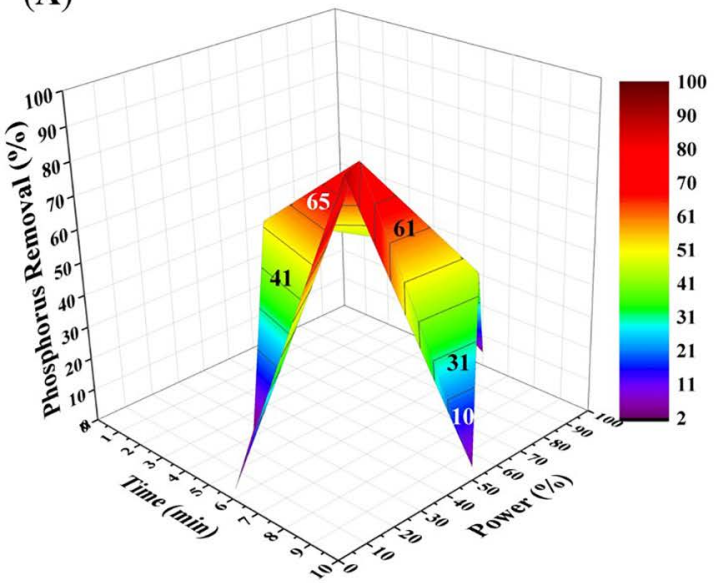

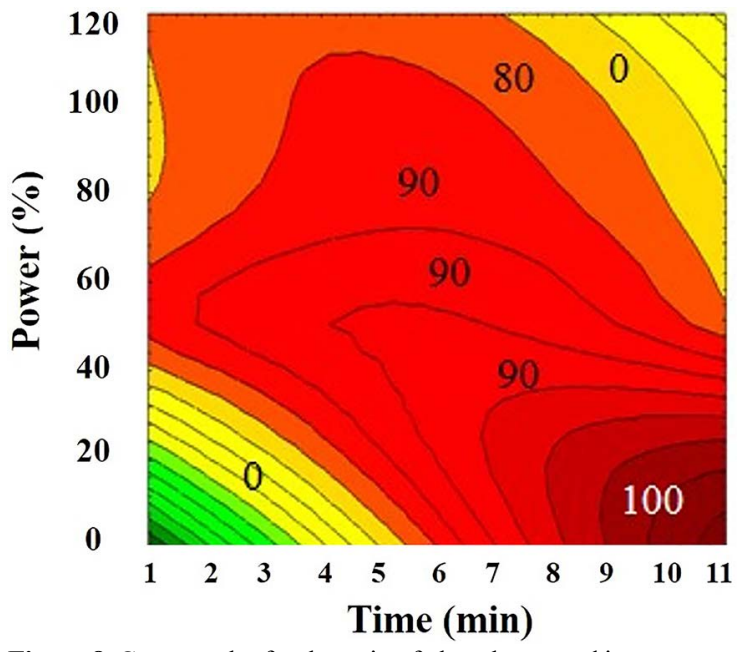

Figure 8. Contour plot for the ratio of phosphorus and iron content removal rates of iron ore particles as a function of the variables of microwave energy and contact time of iron ore samples percolated with $25 \mathrm{~g}$ of sulfuric acid on $50 \mathrm{~g}$ of iron ore.

This result confirms that the effect of heating time on the dissolution of the metals was of great importance, and temperature values of $300^{\circ} \mathrm{C}$ with 1.2 times the stoichiometric values of sulfuric acid for different time intervals between 1 and 6 min were found ${ }^{24}$.

Figures $9 \mathrm{~A}$ and $\mathrm{B}$ show the $2 \mathrm{~d}$ profiles of phosphorus and iron content reduction as a function of sample contact time with microwave energy and the power applied by the furnace in the percolated iron ore sample.

It is observed that high rates of removal can be obtained by combinations of lower power and longer contact times with the microwave energy. It was also observed that high percentages of phosphorus removal were obtained in time values between 7 - 11 min, using between 30 and $60 \%$ of the maximum power of the microwave oven.

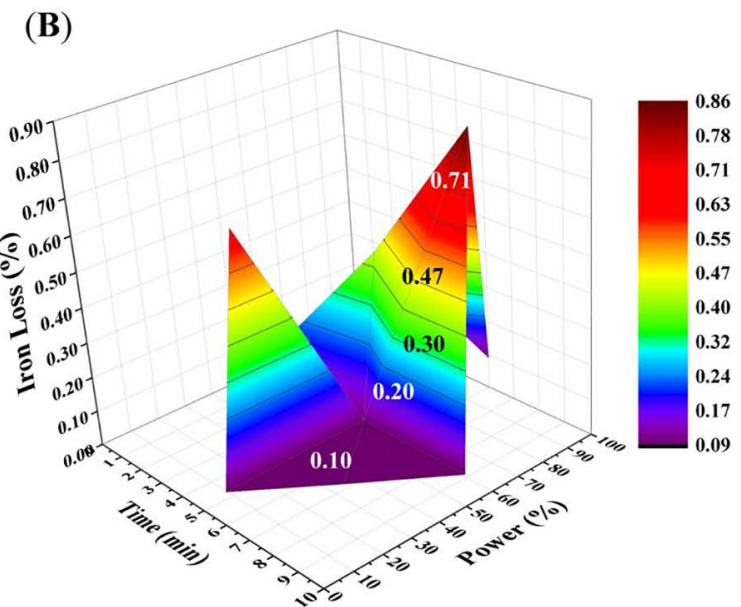

Figure 7. Removal of phosphorus (A) and iron loss (B), as a function of contact time of the sample particles with the microwave energy and the power applied by the furnace to the iron ore particles. 
A

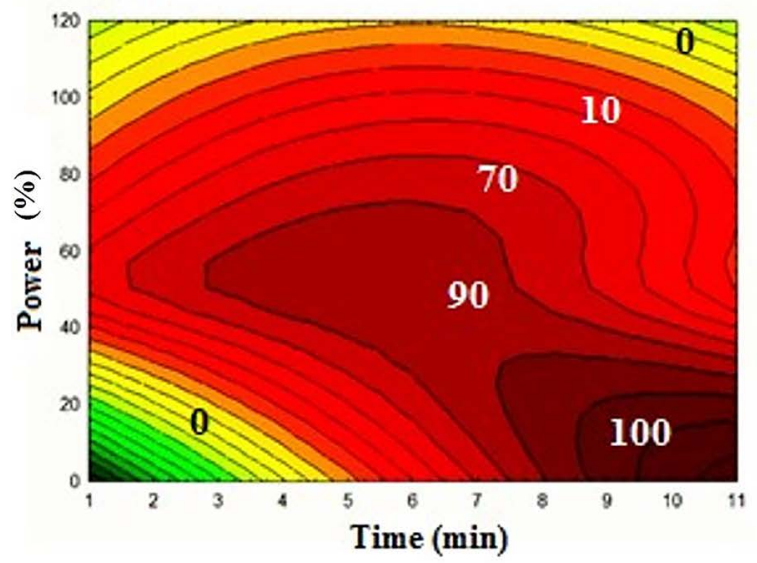

B

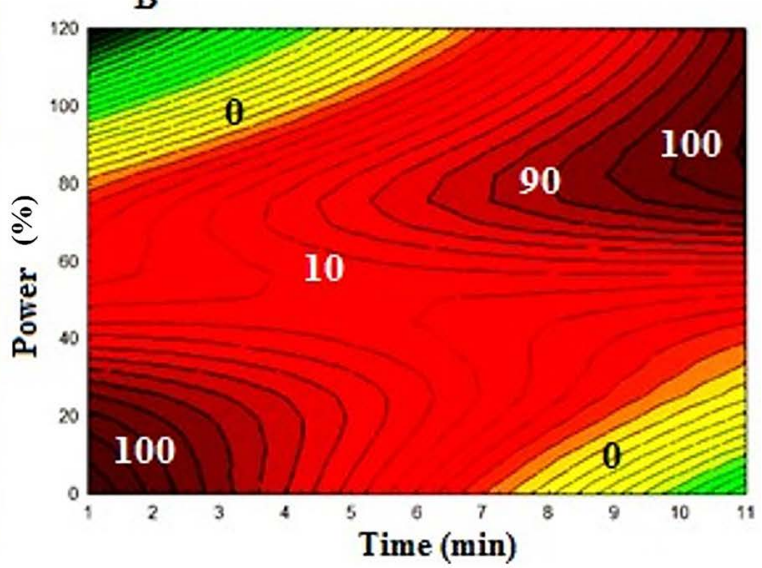

Figure 9. Contours of the percentage of iso-values of the phosphorus (A) and iron (B) content removal as a function of the sample contact time with the microwave energy and the power applied by the furnace to the sample of percolated iron ore.

The results indicated that the power supplied by the microwave oven should have intermediate values showing that the heating has a moderate rate so that the acid has a longer contact time with the iron ore particles. It was observed that the contact time has a significant influence on the reduction of the phosphorus content of the iron ore particles. The best results indicated constant progress in the contact time of the sulfuric acid with the iron ore particles. Fractures in the ore particles occur throughout the grain boundary between absorbent and transparent species ${ }^{25}$. Direct leaching with sulfuric acid was deemed inefficient for metal removal ${ }^{22}$. However, a large excess of acid and/ or longer leaching time was considered to be necessary to achieve dissolution of $>90 \%$ of all metals. However, it has also been observed that the process requires a large excess of acid ( $>4.5$ times the stoichiometry) and the permanence of the batch mixture at temperatures between 250 and $300^{\circ} \mathrm{C}$ for a period of $2 \mathrm{~h}^{22}$. For total acid consumption, baking and leaching time will have to be about 1.5 times the stoichiometric time. This might be explained by the evaporation rate of the sulfuric acid (boiling point $338^{\circ} \mathrm{C}$ ), which exceeds the sulfation rate of these metal oxides at temperatures above the boiling point. However, in order to meet the increase of the contact surface, microwave energy offers this great advantage in view of the $100 \%$ removal rate of the phosphorus element from the iron ore particles, with the microwave induced stress in materials strongly depending on the presence of absorbent phases in the microstructure. Sufficiently strong heating triggers a phase transformation in the quartz grains, which leads to even higher stresses in both constituents. Thus, a different fracture pattern is expected in the anisotropic case. The phase transformations, as well as the anisotropic behavior of the quartz crystals, have great potential to promote fractures.
The effect of heating time on the percentage of dissolution of the metals was of great importance having found temperature values of $300^{\circ} \mathrm{C}, 1.2$ times the stoichiometric amounts of sulfuric acid in different time intervals between 1 and $6 \mathrm{~h}^{24}$. Higher amounts of removal of the phosphorus and iron content were demonstrated in samples of iron ore under the leaching time between 1-2 minutes. Who stated that the rapid heating of the ore particles occurred through the application of microwave energy in a transparent matrix, which generates thermal stress of sufficient magnitude to create microcracks along the grain boundaries of the minerals ${ }^{13}$. This type of microcracks has great potential for improving the efficiency of the comminution and leaching processes. However, the rate of phosphorus removal is intense during the initial 10 minutes of acid leaching and decrease during the reaction time between 10 and $60 \mathrm{~min}$, these results agree with the previous repor ${ }^{25}$. The occurrence of two stages was observed, which indicated that the mass transfer coefficient of the two phases is different. The initial mass transfer coefficient (0-10 min) was measured higher than in the second stage of mass transfer (10 - $60 \mathrm{~min}$ ). Several trends of dephosphorization mechanisms at different stages were investigated. Higher kinetics of the reaction, as well as, lower acid consumption are other benefits presented in this route about the use of the direct sulfuric acid leaching, as reported in the traditional processes of treatment by acid leaching ${ }^{26-31}$

\subsection{Analysis of the control stage of the phosphorus and iron content processes of iron ore particles percolated with sulfuric acid and submitted to the action of the microwave energy}

Figure 10 shows the chemical and diffusional control step for phosphorus removal kinetics in iron ore samples with a grain size variation of more than $0.234 \mathrm{~mm}$. 


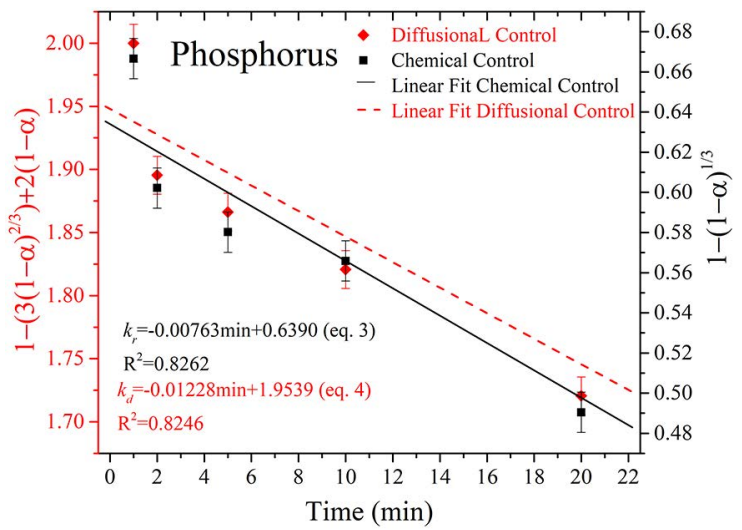

Figure 10. Chemical and diffusional controls plots for the kinetics of phosphorus removal in samples of iron ore with particle size sieved greater than $0.234 \mathrm{~mm}$

The reaction rate controlling step was evaluated in samples of $50 \mathrm{~g}$ of iron ore with an average particle size sieved over than $0.234 \mathrm{~mm}$ and percolated with $25 \mathrm{~g}$ of sulfuric acid during 10 minutes in a furnace with power levels of $50 \%$ of the total microwave emission capacity. Figure 10 shows the evaluation of the chemical control step for kinetics of phosphorus removal in samples of iron ore with particles size over than 0.234 $\mathrm{mm}$. The correlation coefficient value of 0.82 was observed. These correlation values for both mechanisms indicated that the reactions take place through the combination of these mechanisms. The mixture of chemical and diffusion controls combine to give the effective action of the acid baking process under the application of microwave energy and facilitates the removal of phosphorus from the iron ores particles. The plausible explanation lies in potentializing the action of different mechanisms with the phosphate structure present in the iron ore particle. Therefore, the leaching mechanisms can be explained in terms of heterogeneous reactions occurring at the interface between the solid particles and the leaching solution ${ }^{32}$. Stages involved in the heterogeneous reactions are: (a) diffusion of the leachate from the solution to the boundary layer of the solution and (b) chemical reaction at the interface. Previous work reported that the kinetics of ferric leaching of the sphalerite contained in concentrates could be explained by two kinetic regimes ${ }^{33}$. The hypothesis of two kinetic regimes agrees with previous work ${ }^{34-38}$, while mixed control (chemical and diffusional) was found by other researchers ${ }^{32,39}$. These controversial results are explained due to that the transformations take place with different mechanisms of decomposition, which depend mainly on the degree of densification of the product layer of the solid ${ }^{6}$. With the aid of microwave, the surface of a solid reactant can be renewed, and the surface area between the reactants increases and continuously renewed, so the control step changes from the internal diffusion to the surface chemical reaction along the reaction time. For the kinetics of $\mathrm{HgS}$ leaching with cuprous thiosulfate solutions, it was found that the leaching process can be a diffusion-controlled, mix, and surface chemical reactions ${ }^{31}$.
Authors report that was observed that the mechanism of diffusion was the mechanism during the first $60 \mathrm{~min}$, and the mechanism of chemical reaction was the dominant mechanism for $60-240 \mathrm{~min}^{40}$. The change in the control mechanism was attributed to the alternation of the solute phase during leaching. With this discussion in mind, we carried out experiments to analyze the iron loss during the leaching period of the proposed route. Figure 11 presents the linear plots of the two mechanisms. As can be observed, the weight loss is negligible during the removal period of treatment. In Figure 11 the evaluation of the chemical and diffusional control step for the kinetics of iron removal in samples with size above of $0.234 \mathrm{~mm}$. As can be observed, the results did not allow to conclude if the mechanism is chemical reaction or diffusion through the product solid layer.

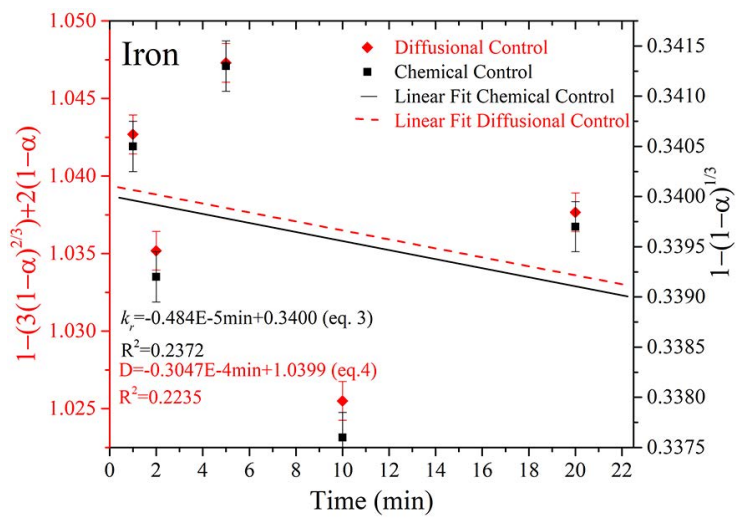

Figure 11. Evaluation of the chemical and diffusional control step for the kinetics of iron removal in samples of iron ore with granulometric variation more significant than $0.234 \mathrm{~mm}$.

These results are of particular interest since the iron loss is not desirable in this process. Therefore, these results attain two beneficial requirements: a) the phosphorus removal process is fast with a low concentration of sulfuric acid and b) under these conditions, the iron loss is negligible. The size of the particle can also induce a decrease of the diffusional control. Larger particles substantially decrease the rate of phosphorus removal. Therefore, it is needed to balance the rate of phosphorus removal with the comminution energy spent. The results obtained using the statistical correlations are useful to attain these requirements. It was also demonstrated that the acid baking process with microwaves could generate fractures in the iron ore particles and enhance the leaching process. However, the larger particles lead to the diffusional control with a slower rate of the leaching reactions.

The interaction of the magnetic field with some materials contributes significantly to the heating rate compared to the materials exposed to the electric field ${ }^{18}$. It has also been suggested that the fracture was caused by the rapid response of the mineral phases and heated in a transparent microwave array. This study confirmed that energy accumulation plays an essential role in fractures, and therefore, it is expected a higher efficiency of the acid leaching process. 


\section{Conclusion}

To evaluate the profile of phosphorus removal and the controlling step of iron ore fines, a statistical and kinetic modeling evaluation, supported by experimental data, were elaborated. Based on the analysis, the following conclusions were drawn:

- The use of microwaves energy allows the high rate of heating and generation of fractures, which increases the contact surface and improve the effectiveness of the sulfuric acid solution.

- The microwave power emission and the exposition time are important parameters for the efficiency of the phosphorous removal process. Higher levels of phosphorus content removal were found to the exposition times above 6 minutes, with power values around $50 \%$ of the microwave oven maximum emission, achieving the $100 \%$ of the removal of the initial phosphorus content.

- The coefficients of correlations indicate that both the chemical in surface and intraparticle diffusion control mechanisms during the leaching step are taking place at the initial and final stages, respectively.

- Conversely, the coefficients of correlations for the iron loss indicated that the mechanism of chemical control did not take place. Furthermore, the amounts of iron losses are very low, which is an advantage of the process, combining the maximum phosphorus removal rate with the minimum iron losses.

\section{Acknowledgments}

The authors thank the funding agencies: Coordination of Improvement of Higher Education Personnel (CAPES). Ministry of Science and Technology. They also thank the Center for Mineral Technology team for the development of chemical tests and analyses, and the Metallurgical Engineering graduate program of the Fluminense Federal University for the scientific-technical support.

\section{References}

1. Cheng CY, Misra VN, Clough J, Muni R. Dephosphorisation of western Australian iron ore by hydrometallurgical process. Minerals Engineering. 1999;12(9):1083-1092.

2. Morris RC. A pilot study of phosphorus distribution in parts of the Brockman iron formation. Western Australia Geological Survey Annual Report 1972. Hamersley: Hamersley Group; 1973.

3. Barbour AR. Distribution of phosphorus in the iron ore deposit of Itabira, Minas Gerais, Brazil. Economic Geology. 1973;68:52-64.

4. Dukino R. Phosphorus in Hamersley Range iron ore. BHP Internal Report. Melbourne: BHP Billiton; 1997.

5. Gooden J E A, Walker W M and Allen R J, 'AMDEPHOS'--A chemical process for dephosphorisation of iron ore, Proceedings of National Chemical Engineering Conference, Queensland, 1974, 21-33..
6. Jin HS, Jiang T, Yang YB, Li Q, Li GH, Guo YF. Removal of phosphorus from iron ores by chemical leaching. Journal of Central South University of Technology. 2006;13(6):673-677.

7. Peixoto G, inventor. Improvement of the reduction process in $P$ content and other gangues in iron ore and its agglomerates. International patent. WO1993010271A2. 1993 May 27.

8. Tang HQ, Wang JW, Guo ZC, Ou T. Intensifying Gaseous Reduction of High Phosphorus Iron Ore Fines by Microwave Pretreatment. Journal of Iron and Steel Research, International. 2013;20(5):17-23.

9. Meisels R, Toifl M, Hartlieb P, Kuchar F, Antretter, T. Microwave propagation and absorption and its thermo-mechanical consequences in heterogeneous rocks. International Journal of Mineral Processing. 2015;135:40-51.

10. Hartlieb P, Toifl M, Kuchar F, Meisels R, Antretter T. Thermophysical properties of selected hard rocks and their relation to microwave-assisted comminution. Minerals Engineering. 2016;91:34-41

11. Jones DA, Kingman SW, Whittles DN, Lowndes IS. Understanding microwave assisted breakage. Minerals Engineering. 2005;18(7):659-669.

12. Romankiw LT. Kinetics of dissolution of zinc sulfide in aqueous sulfuric acid. [PhD Thesis]. Cambridge: Massachusetts Institute of Technology; 1962.

13. Haque KE. Microwave energy for mineral treatment processesbrief review. International Journal of Mineral Processing. 1999;57(1):1-24.

14. Demol J, Ho E, Senanayake G. Sulfuric acid baking and leaching of rare earth elements, thorium and phosphate from a monazite concentrate: Effect of bake temperature from 200 to $800^{\circ} \mathrm{C}$. Hydrometallurgy. 2018;179:254-267.

15. Krug FJ. Métodos de Decomposição de Amostras. In: $V$ Workshop sobre Preparo de Amostras; 2004 Oct 18-22; São Paulo, SP, Brazil.

16. Huang XW, Long ZQ, Wang LS, Feng ZY. Technology development for rare earth cleaner hydrometallurgy in China. Rare Metals. 2015;34(4):215-222.

17. Zhang $P$, Inoue $K$, Tsuyama $H$. Recovery of metal values from spent hydro-desulfurization catalysts by liquid-liquid extraction. Energy \& Fuels. 1995;9(2):231-239.

18. Peelamedu RD, Roy R, Agrawal D. Anisothermal reaction synthesis of garnets, ferrites, and spinels in microwave field. Materials Research Bulletin. 2001;36(15):2723-2739.

19. Walkiewicz JW, Kazonich G, McGill SL. Microwave heating characteristics of selected minerals and compounds. Minerals \& Metallurgical Processing. 1988;5(1):39-42.

20. Kingman SW, Jackson K, Cumbane A, Bradshaw SM, Rowson NA, Greenwood R. Recent developments in microwave-assisted comminution. International Journal of Mineral Processing. 2004;74(1-4):71-83.

21. Graham J. Phosphorus in iron ore from the Hamersley iron formations. Proceedings of the Australasian Institute of Mining and Metallurgy. 1973;246:41-42.

22. Yang JH, He LH, Liu XH, Ding WT, Song YF, Zhao ZW. Comparative kinetic analysis of conventional and ultrasoundassisted leaching of scheelite by sodium carbonate. Transactions of Nonferrous Metals Society of China. 2018;28(4):775-782. 
23. Levenspiel O. Chemical Reaction Engineering. $3^{\text {rd }}$ ed. New York: John Wiley \& Sons; 1999.

24. Kim HI, Park KH, Mishra D. Sulfuric acid baking and leaching of spent $\mathrm{Co}-\mathrm{Mo} / \mathrm{Al}_{2} \mathrm{O}_{3}$ catalyst. Journal of Hazardous Materials. 2009; 166(2-3):1540-1544.

25. Wang J, Shen S, Kang J, Li H, Guo Z. Effect of ore solid concentration on the bioleaching of phosphorus from highphosphorus iron ores using indigenous sulfur-oxidizing bacteria from municipal wastewater. Process Biochemistry. 2010;45(10):1624-1631.

26. Mason TJ. Sonochemistry and the environment - Providing a "green" link between chemistry, physics and engineering. Ultrasonics Sonochemistry. 2007;14(4):476-483.

27. Ionkov K, Gaydardzhiev S, Araujo AC, Bastin, D, Lacoste M. Amenability for processing of oolitic iron ore concentrate for phosphorus removal. Miner. Eng. 46-47, 119-127.

28. Li JT, Zhao ZW, Ding WT. Kinetics of scheelite concentrate leached by sodium phosphate under ultrasound. The Chinese Journal of Nonferrous Metals. 2014;24(6):1607-1615.

29. Zhao ZW, Li HG. Thermodynamics for Leaching of Scheelite: Pseudo-Ternary-System Phase Diagram and Its Application. Metallurgical and Materials Transactions B. 2008;39(4):519-523.

30. Martins JP, Martins F. Soda ash leaching of scheelite concentrates: the effect of high concentration of sodium carbonate. Hydrometallurgy. 1997;46(1-2):191-203.

31. Zhao TC, Wang J. A Handbook for extractive metallurgy of nonferrous metals. Beijing: Metallurgical Industry Press; 1999.
32. Bobeck GE, Su H. The kinetics of dissolution of sphalerite in ferric chloride solution. Metallurgical Transactions $B$. 1985;16(3):413-424.

33. Lorenzo-Tallafigo J, Iglesias-Gonzalez N, Romero R, Mazuelos A, Carranza F. Ferric leaching of the sphalerite contained in a bulk concentrate: Kinetic study. Minerals Engineering. 2018;125:50-59.

34. Souza AD, Pina PS, Leão VA, Silva CA, Siqueira PF. The leaching kinetics of a zinc sulphide concentrate in acid ferric sulphate. Hydrometallurgy. 2007;89(1-2):72-81.

35. Lochmann J, Pedíik M. Kinetic anomalies of dissolution of sphalerite in ferric sulfate solution. Hydrometallurgy. 1995;37(1):89-96

36. Weisener CG, Smart RSTC, Gerson AR. Kinetics and mechanisms of the leaching of low Fe sphalerite. Geochimica et Cosmochimica Acta. 2003;67(5):823-830.

37. Crundwell FK. Kinetics and mechanism of the oxidative dissolution of a zinc sulphide concentrate in ferric sulphate solutions. Hydrometallurgy. 1987;19(2):227-242.

38. Karimi S, Rashchi F, Moghaddam J. Parameters optimization and kinetics of direct atmospheric leaching of Angouran sphalerite. International Journal of Mineral Processing. 2017;162:58-68.

39. da Silva G. Relative importance of diffusion and reaction control during the bacterial and ferric sulphate leaching of zinc sulphide. Hydrometallurgy. 2004;73(3-4):313-324.

40. Hosseini SA, Raygan S, Rezaei A, Jafari A. Leaching of nickel from a secondary source by sulfuric acid. Journal of Environmental Chemical Engineering. 2017;5(4):3922-3929. 